\title{
Perineurial Glia Require Notch Signaling during Motor Nerve Development but Not Regeneration
}

\author{
Laura A. Binari, Gwendolyn M. Lewis, and Sarah Kucenas \\ Department of Biology, University of Virginia, Charlottesville, Virginia 22904
}

\begin{abstract}
Motor nerves play the critical role of shunting information out of the CNS to targets in the periphery. Their formation requires the coordinated development of distinct cellular components, including motor axons and the Schwann cells and perineurial glia that ensheath them. During nervous system assembly, these glial cells must migrate long distances and terminally differentiate, ensuring the efficient propagation of action potentials. Although we know quite a bit about the mechanisms that control Schwann cell development during this process, nothing is known about the mechanisms that mediate the migration and differentiation of perineurial glia. Using in vivo imaging in zebrafish, we demonstrate that Notch signaling is required for both perineurial migration and differentiation during nerve formation, but not regeneration. Interestingly, loss of Notch signaling in perineurial cells also causes a failure of Schwann cell differentiation, demonstrating that Schwann cells require perineurial glia for aspects of their own development. These studies describe a novel mechanism that mediates multiple aspects of perineurial development and reveal the critical importance of perineurial glia for Schwann cell maturation and nerve formation.
\end{abstract}

\section{Introduction}

A fundamental goal in neuroscience is to understand what controls cell migration. Unlike other organ systems where cells are restricted to a discrete space, peripheral glia must migrate long distances from their origin to their target. This migration, controlled by interpreting cell-cell interactions and environmental cues, ensures that distinct nerve components coalesce and establish functional neural circuits.

In Drosophila, most peripheral glia originate within the ventral nerve cord and migrate as chains along motor axons (Sepp et al., 2000, 2001). Once in the periphery, leader cells are required for directed migration of the chain (Sepp et al., 2000, 2001). In zebrafish, Schwann cells along the posterior lateral line nerve (PLLn) also use chain migration and display a complete dependence on axons for migration cues (Gilmour et al., 2002). Recently, however, analysis of the role of motor axons in segmental neural crest migration, including Schwann cell precursors, demonstrated that motor axons are dispensable for segmental migration (Banerjee et al., 2011). These results suggest that there are mechanisms mediating peripheral glial migration that are axon

Received Oct. 17, 2012; revised Jan. 1, 2013; accepted Jan. 9, 2013.

Author contributions: L.A.B., G.M.L., and S.K. designed research; L.A.B., G.M.L., and S.K. performed research; L.A.B., G.M.L., and S.K. analyzed data; L.A.B., G.M.L., and S.K. wrote the paper.

This work was supported by National Institutes of Health Grant NS072212 (S.K.), March of Dimes Grant5-FY11-90 (S.K.), and the University of Virginia Fund for Excellence in Science and Technology (FEST) Award (S.K.). We thank members of the Kucenas laboratory for valuable discussions, Sarah Kempke and Silvia Barrett for zebrafish care, and Mark Voigt, Jane Cox, and Jay Hirsh for comments on the manuscript. In addition, we thank the following investigators for their gifts of fish lines: Dr. Michael Parsons-Tg(Tp1bglob:hmgb1-mcherry) ${ }^{j h 11}$, Dr. Ajay ChitnisTg(her4:EGFP) and Tg(her4:DRFP), and Dr. Didier Stainier-Tg(hsp:ZdnSu(H)-myc;hsp:gfp).

Correspondence should be addressed to Sarah Kucenas, Department of Biology, Physical and Life Sciences Building, Room 312, P0 Box 400328, University of Virginia, Charlottesville, VA 22904-4328. E-mail: sk4ub@virginia.edu. DOI:10.1523/JNEUROSCI.4893-12.2013

Copyright $\odot 2013$ the authors $\quad 0270-6474 / 13 / 334241-12 \$ 15.00 / 0$ independent. However, to date, nothing is known about these nonaxonal mechanisms.

In zebrafish, perineurial glia originate from precursors in the floor plate ( $\mathrm{p} 3$ domain) of the spinal cord, migrate out of the CNS via motor axon exit points (MEPs), and associate with outgrowing motor axons and Schwann cells in the periphery (Kucenas et al., 2008). Previous studies have demonstrated that these cells require Schwann cells for their exit from the spinal cord (Kucenas et al., 2008, 2009). However, the nature of the Schwann cell-derived signal and whether there are other mechanisms that mediate perineurial glial migration are still unknown. Recently, a screen looking for mutations affecting peripheral glial migration in Drosophila identified mutations in Notch signaling cascade components (Edenfeld et al., 2007). These data, in conjunction with the well known role that Notch plays in peripheral glial development in vertebrates (Wang and Barres, 2000; Jessen and Mirsky, 2002; Taylor et al., 2007; Mirsky et al., 2008; Woodhoo et al., 2009), led us to hypothesize that Notch might control perineurial glial migration in zebrafish. To test this hypothesis, we used a combination of pharmacological inhibitors and transgenic lines to impair Notch signaling.

From these studies, we show that Notch signaling is required for perineurial glial migration and differentiation during development, and perturbations to these events adversely affect Schwann cell differentiation. We also sought to investigate whether perineurial glia use Notch signaling after injury, as they have been reported to be critical players during regeneration. Intriguingly, we never observed Notch activity in perineurial glia along injured nerves, suggesting that the mechanisms that build the PNS are not the same as those that mediate regeneration. These data describe a novel mechanism governing the migration and differentiation of vertebrate perineurial glia during develop- 
Table 1. Descriptions and abbreviations of transgenic lines used in this study

\begin{tabular}{|c|c|c|c|}
\hline Transgene name & Transgene abbreviation & Cells labeled & Transgene action \\
\hline $\operatorname{Tg}(n k x 2.2 a: m e g f p)$ & $\operatorname{Tg}(n k \times 2.2 a: e g f p)$ & Floorplate, $\mathrm{OPCS}$, and perineurial glia & EGFP expression in $n k x 2.2 a^{+}$cells \\
\hline $\operatorname{Tg}(o l i g 2: d s r e d 2)$ & Tg(olig2:dsred) & Motor neurons/axons and OPCs & DsRed expression in olig2 ${ }^{+}$cells \\
\hline $\operatorname{Tg}($ sox10(7.2):mrfp) & $\operatorname{Tg}$ (sox10:mrfp) & Schwann cells and OPCs & RFP expression in sox $10^{+}$cells \\
\hline Tg(T2KTp1bglob:hmgb1-mCherry) & $\operatorname{Tg}(T p 1: m c h e r r y)$ & Cells actively using Notch signaling & mCherry expression in cells actively using Notch pathway \\
\hline $\operatorname{Tg}($ her4:EGFP) & $\operatorname{Tg}$ (her4:egfp) & Cells actively using Notch signaling & EGFP expression in cells actively using Notch pathway \\
\hline $\operatorname{Tg}($ her4:dRFP) & $\operatorname{Tg}$ (her4:drfp) & Cells actively using Notch signaling & Destabilized RFP expression in cells actively using Notch pathway \\
\hline Tg(hsp701:Gal4)1.5; Tg(UAS:myc-Notch1a-intra) & Tg(hsp:gal4);Tg(UAS:Notch1a-intra) & Nearly ubiquitous upon heat shock & Constitutively active Notch signaling upon heat shock \\
\hline $\operatorname{Tg}(h s p: Z d n S u(H)-m y c ; h s p: G F P)$ & $\operatorname{Tg}(h s p: d n S u(H): g f p)$ & Nearly ubiquitous upon heat shock & Notch signaling inhibition upon heat shock \\
\hline
\end{tabular}

All lines used were stable, germline transgenics. Cell types listed for each transgene are only those pertinent to this study.

ment, and reveal that perineurial cells are essential for Schwann cell maturation and motor nerve assembly.

\section{Materials and Methods}

Fish husbandry. All animal studies were approved by the University of Virginia Institutional Animal Care and Use Committee. Zebrafish strains used in this study included $\mathrm{AB}^{*}, \operatorname{Tg}(n k x 2.2 a: \text { megfp })^{v u 17}$ (Kirby et al., 2006; Kucenas et al., 2008) abbreviated $\operatorname{Tg}(n k x 2.2 a$ :egfp), $\operatorname{Tg}(\operatorname{sox} 10(7.2)$ : $m r f p)^{\text {vu234 }}$ (Kucenas et al., 2008) abbreviated $\operatorname{Tg}($ sox10:mrfp), $\operatorname{Tg}($ olig2: dsred2) ${ }^{v u 19}$ (Kucenas et al., 2008) abbreviated Tg(olig2:dsred), $\operatorname{Tg}$ (hsp: $Z d n S u(H)-m y c ; h s p: g f p)^{S 941}$ (Ninov et al., 2012) abbreviated $\mathrm{Tg}(h s p$ : $d n S u(H): g f p), \operatorname{Tg}(T 2 K T p 1 b g l o b: h m g b 1-m c h e r r y)^{j h 11}$ (Parsons et al., 2009) abbreviated $\operatorname{Tg}$ (Tp1:mcherry), $\operatorname{Tg}$ (her4:EGFP) (Yeo et al., 2007) abbreviated $\operatorname{Tg}$ (her4:egfp), $\operatorname{Tg}($ her4:dRFP) (Yeo et al., 2007) abbreviated $\operatorname{Tg}$ (her4: $d r f p), \operatorname{Tg}(h s p 70 l: G a l 4) 1.5^{k c a 4}$ (Scheer et al., 2001) abbreviated $\operatorname{Tg}$ (hsp:Gal4), and $\operatorname{Tg}(\text { UAS:myc-Notchla-intra) })^{k c a 3}$ (Scheer et al., 2001) abbreviated $\operatorname{Tg}($ UAS:Notch1a-intra). Table 1 describes the expression and action of all of these transgenic lines. Embryos were produced by pairwise matings, raised at $28.5^{\circ} \mathrm{C}$ in egg water, staged according to hours postfertilization (hpf), and embryos of either sex were used for all experiments described below (Kimmel et al., 1995). Embryos used for in situ hybridization, immunocytochemistry, and microscopy were treated with $0.003 \%$ phenylthiourea (PTU) in egg water to reduce pigmentation.

In vivo imaging. At $24 \mathrm{hpf}$, all embryos used for live imaging were manually dechorionated and transferred to egg water containing PTU to block pigment formation. At specified stages, embryos were anesthetized using 3-aminobenzoic acid ester (Tricaine), immersed in $0.8 \%$ lowmelting point agarose and mounted on their sides in glass-bottomed 35 $\mathrm{mm}$ Petri dishes (Electron Microscopy Sciences). All images were captured using a $25 \times$ multi-immersion objective (numerical aperture $=$ 0.8 ) or a $63 \times$ oil objective (numerical aperture $=1.2$ ) mounted on a motorized Zeiss AxioObserver Z1 microscope equipped with a Quorum WaveFX-X1 spinning disc confocal system (Quorum Technologies Inc.). During time-lapse experiments, a heated stage chamber was used to maintain embryos at $28.5^{\circ} \mathrm{C}$. $Z$ image stacks were collected every $20 \mathrm{~min}$, and three-dimensional datasets were compiled using Sorenson 3 video compression (Sorenson Media) and exported to QuickTime (Apple) to create movies.

Chemical treatments. Stock solutions for DAPT (565784; $N$ - [(3,5difluorophenyl)acetyl]-L-alanyl-2-phenyl]glycine-1,1-dimethylethyl ester; EMD Chemicals) were made in DMSO and used at $100 \mu \mathrm{M}$. DAPT was diluted in PTU egg water plus DMSO to a final concentration of $1 \%$ DMSO and mixed by vortexing. Larvae were placed in $3 \mathrm{ml}$ of PTU egg water containing DAPT in $35 \mathrm{~mm}$ Petri dishes. Control larvae were placed in $3 \mathrm{ml}$ of PTU egg water containing 1\% DMSO alone. When assessing perineurial phenotype, at least 6 nerves from the mid-trunk of each larva were observed.

Heat shock experiments. Heat shock was applied to transgenic and control larvae in egg water for $30 \mathrm{~min}$ at $40^{\circ} \mathrm{C}$ to induce transgene expression. Following heat shock, embryos were incubated at $28.5^{\circ} \mathrm{C}$. We confirmed identification of $T g(h s p: d n S u(H): g f p)$ mutant larvae by confirming expression of GFP (Ninov et al., 2012). Larvae from crosses of $\operatorname{Tg}$ (hsp:Gal4) and $\operatorname{Tg}(n k x 2.2 a: e g f p) ; \operatorname{Tg}($ UAS:Notch1a-intra) fish were heat-shocked at $36 \mathrm{hpf}$ and incubated in DMSO or DAPT until $72 \mathrm{hpf}$. Overexpression of myc-Notch1a-intra at 3 days postfertilization (dpf) was verified by the expression of anti-Myc staining (data not shown). When assessing perineurial phenotype, at least 6 nerves from the midtrunk of each larva were observed. Because the phenotypes we observed with DAPT treatment and heat shock of the $T g(h s p: d n S u(H): g f p)$ line were identical, we chose to do most of our analysis in DAPT-treated larvae as they allowed for clearer in vivo imaging without background GFP expression.

In situ RNA hybridization. Larvae were fixed in $4 \%$ paraformaldehyde for $24 \mathrm{~h}$, stored in $100 \%$ methanol at $-20^{\circ} \mathrm{C}$, and processed for in situ RNA hybridization. Plasmids were linearized with appropriate restriction enzymes and cRNA preparation was performed using Roche DIGlabeling reagents and SP6 RNA polymerase (New England Biolabs). After in situ hybridization, embryos were embedded in $1.5 \%$ agar $/ 30 \%$ sucrose and frozen in 2-methylbutane chilled by immersion in liquid nitrogen. Transverse sections $(20 \mu \mathrm{m})$ were collected on microscope slides using a cryostat microtome and covered with $75 \%$ glycerol. Images were obtained using a Zeiss AxioCam CCD camera mounted on a Zeiss AxioObserver Z1 microscope equipped with Zeiss AxioVision software. All images were imported into Adobe Photoshop. Adjustments were limited to levels, contrast, color matching settings, and cropping.

Immunohistochemistry. Embryos and larvae were fixed in AB Fix (4\% paraformaldehyde, $8 \%$ sucrose, $1 \times \mathrm{PBS}$ ) for $3 \mathrm{~h}$ at $23^{\circ} \mathrm{C}$ or overnight at $4^{\circ} \mathrm{C}$ and embedded as described above. We collected $20 \mu \mathrm{m}$ transverse sections using a cryostat microtome. Sections were rehydrated in $1 \times \mathrm{PBS}$ for $60 \mathrm{~min}$ at $23^{\circ} \mathrm{C}$ and preblocked in $2 \%$ goat serum/BSA $/ 1 \times$ PBS for 30 $\min$. Sections were incubated in primary antibody overnight at $4^{\circ} \mathrm{C}$. The primary antibodies used included mouse anti-acetylated tubulin (1: 10,000, Sigma), rabbit antibody to Sox10 (1:5000, generated commercially against the peptide sequence CHWEQPVYTTLSRP, Open Biosystems), mouse anti-c-Myc (Santa Cruz Biotechnology, 1:100) and mouse antibody to ZO-1 (zona occludins 1; Zymed, 1:200). Sections were washed extensively with $1 \times \mathrm{PBS}$, incubated for $3 \mathrm{~h}$ at $23^{\circ} \mathrm{C}$ with either Alexa Fluor 647 goat anti-rabbit or Alexa Fluor 568 goat antimouse (Invitrogen) as secondary antibodies for detection of primary antibodies, and washed with $1 \times$ PBS for $30 \mathrm{~min}$. Sections were mounted in Vectashield (Vector Laboratories) and imaged using the confocal microscope described above. Image adjustments were limited to contrast enhancement and level settings using MetaMorph software and Adobe Photoshop.

Data quantification and statistical analysis. To count cells in experimental and control larvae, composite $Z$ image stacks were compiled using MetaMorph software. Cell counts were taken from transverse section views of the spinal cord. Individual $z$ images were sequentially observed and cells counted within the entire $z$ stack. All graphically presented data represent the mean of the analyzed data. Statistical analyses were performed with GraphPad Prism software. The level of significance was determined by using an unpaired $t$ test using a confidence interval of $95 \%$.

Nerve transection. Nerve transections were performed using a MicroPoint Laser (Photonic Instruments) as previously published (Banerjee et al., 2011), attached to a spinning disk confocal system (Quorum Technologies Inc.) consisting of a nitrogen-pumped dye laser (wavelength 435 $\mathrm{nm}$ ) controlled by MetaMorph version 7.7. Ablation laser settings ranged from power 40 to 70 depending on the age of the larvae and nerve position. One to two motor nerves per larva in hemisegments 10-16 were 


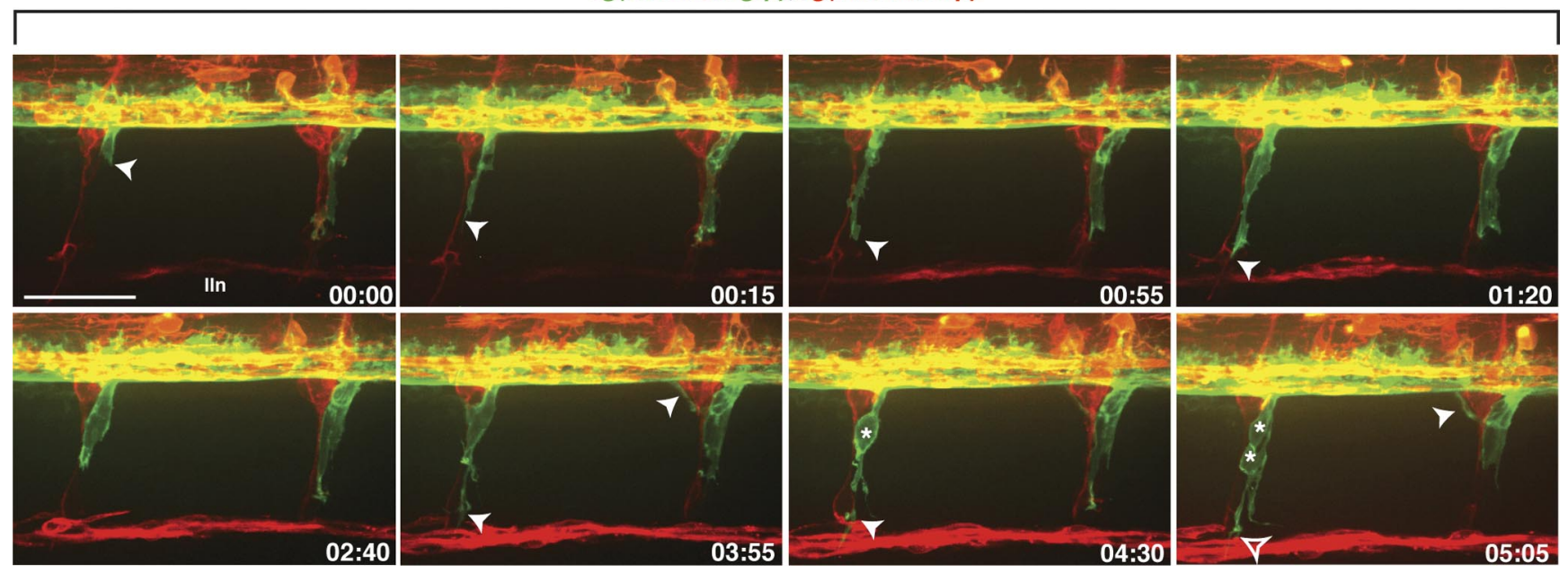

Figure 1. Perineurial glia migrate as a chain out of the spinal cord. Frames captured from a $24 \mathrm{~h}$ time-lapse movie of a wild-type $\operatorname{Tg}(\mathrm{nkx2.2a:egfp);} \mathrm{Tg}(\mathrm{sox} 10$ :mrfp) larva beginning at 48 hpf. Numbers in lower right corners denote time elapsed from the first frame of the figure. At $\sim 50 \mathrm{hpf}\left(00: 00\right.$ time point), $n k x 2.2 a^{+}$perineurial glia (arrowhead) exited the spinal cord next to sox $10^{+}$(red) Schwann cells. Migrating perineurial cells had very few filopodia-like projections and traveled as a chain of cells along motor nerves. Once in the periphery, perineurial glial cell bodies often divided (asterisks) and lead cells had directed membrane processes (open arrowhead) while follower cells did not. Images are lateral views of the spinal cord with dorsal to the top and anterior to the left. lin, Lateral line nerve. Scale bar, $50 \mu \mathrm{m}$.

transected in all experiments. To transect nerves, a thin rectangular ROI was drawn digitally in MetaMorph over the image of the nerve, and the nerve was laser pulsed precisely within the ROI until the nerve appeared transected, whereby fluorescence did not refill the ROI in $>10$ s. Successful transections with this protocol were independently confirmed by identifying the presence of axonal degeneration in transgenic lines that label motor axons (data not shown). In vivo imaging of transected nerves was performed as described above. Following imaging at 3-4 h postinjury, larvae were demounted, allowed to recover overnight in PTU, and remounted for imaging at $20-21 \mathrm{~h}$ postinjury.

\section{Results}

\section{Perineurial glia migrate as a chain in zebrafish larvae}

During embryogenesis, peripheral glia migrate and proliferate extensively along motor and sensory axons before terminally differentiating. One class of these glia, perineurial glia, originate within the ventral spinal cord and make their way into the PNS before eventually forming the mature motor nerve perineurium (Kucenas et al., 2008). At $\sim 17 \mathrm{hpf}$, perineurial glia extend thin membrane processes into the periphery via MEPs, immediately behind the motor axon growth cones (Kucenas et al., 2008). By 48 hpf, perineurial cell bodies exit and follow their membrane processes into the PNS (Kucenas et al., 2008). Using $\operatorname{Tg}(n k x 2.2 a$ : egfp); $T g($ sox 10:mrfp) larvae, where upstream regulatory elements of the $n k \times 2.2 a$ and sox10 genes drive expression of membraneEGFP in perineurial glia and membrane-RFP in Schwann cells, we further characterized perineurial glial migration using timelapse imaging between 48 and $72 \mathrm{hpf}$. Along each motor nerve, we observed a single leader cell exit the CNS with membrane protrusions oriented toward the path of migration (Fig. 1, Movie 1). These cells were always physically associated with follower cells that had very little process activity, and both cell types traveled in unison down motor nerves (Fig. 1, Movie 1). Occasionally, we observed lead cells dividing and giving rise to a cell that maintained the lead position and a cell that followed (Fig. 1, Movie 1). This migration pattern was very robust, occurring along every motor nerve in the larva, and was similar to that described for Drosophila peripheral glia.

\section{Notch signaling is active in migratory perineurial glia}

Currently, there are no known molecular mechanisms that mediate perineurial migration from the CNS. Previous studies have

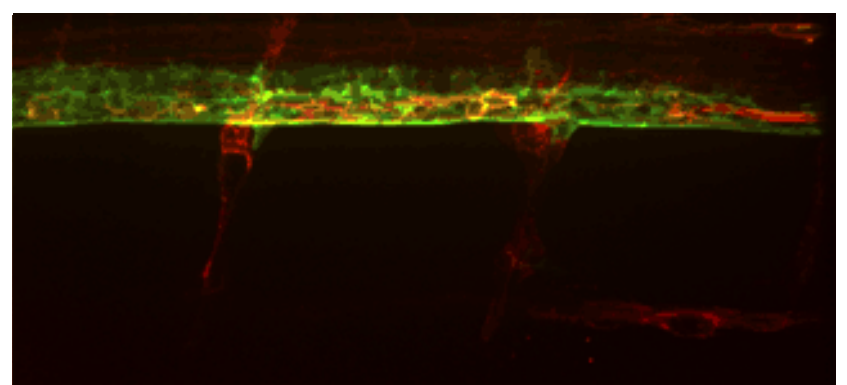

Movie 1. Perineurial glia migrate out of the spinal cord as a chain. In a wild-type larva beginning at $\sim 48 \mathrm{hpf}$, perineurial glia migrate as a chain out of the spinal cord into the periphery via MEPs. They travel alongside Schwann cells, proliferate, and remain associated with motor nerves throughout the movie.

demonstrated that Schwann cell occupation of motor nerves is required, but the mechanisms that draw these glia into the periphery are unknown (Kucenas et al., 2008, 2009). Recently, work in Drosophila has implicated Notch signaling in directing peripheral glial migration (Edenfeld et al., 2007). Therefore, we hypothesized that Notch played a similar role in zebrafish and was necessary for perineurial glial migration out of the CNS. To determine whether Notch activity was present in perineurial glia during their migration, we used the $\operatorname{Tg}$ (her4:egfp), $\operatorname{Tg}($ her4:drfp), and $\operatorname{Tg}(T p 1: m c h e r r y)$ Notch reporter lines in conjunction with various transgenic zebrafish and antibodies that label peripheral nerve components (Yeo et al., 2007; Parsons et al., 2009).

Canonical Notch signaling is activated by a series of proteolytic cleavages of the Notch receptor, which culminates with the intramembrane portion, known as the Notch intracellular domain (NICD), being released into the cytoplasm of the cell (Bray, 2006; Andersson et al., 2011). Once released from the membrane, the NICD is translocated to the nucleus where it binds with its cofactor, RBP-J $\kappa$, also known as Suppressor of Hairless $\mathrm{Su}(\mathrm{H})$ in Drosophila, and subsequently activates the transcription of Notch target genes (Bray, 2006; Andersson et al., 2011). Hairy-related 4 (her4) is one such target of Notch activation in zebrafish and her4 transgenic lines have previously been used as accurate readouts of Notch activity (Takke et al., 1999; Yeo et al., 2007). In a similar 
fashion, the $\operatorname{Tg}(T p 1$ :mcherry) line drives mCherry expression when the NICD and its cofactor, RBP-J $\kappa$, bind to sites present within a Tp1 element (multiple RBP-J $\kappa$ binding sites in front of a minimal promoter) (Parsons et al., 2009; Ninov et al., 2012).

Notch has many actions during Schwann cell development, including stimulating Schwann cell precursor formation and proliferation during embryogenesis, as well as negatively regulating myelination and playing a role in Schwann cell transdifferentiation after injury (Wang and Barres, 2000; Jessen and Mirsky, 2005; Taylor et al., 2007; Woodhoo et al., 2009). Therefore, we first set out to confirm that Notch activity, as represented by the above-mentioned transgenic lines, was observed early in Schwann cell development. At $20 \mathrm{hpf}$, Notch activity was detected in Sox $10^{+}$neural crest cells migrating onto nascent motor nerves in $T g$ (Tp1:mcherry) embryos labeled with an antibody specific to Sox10 (data not shown). In vivo imaging of $T g(\operatorname{sox} 10: m r f p)$; $\operatorname{Tg}$ (her4:egfp) embryos at $24 \mathrm{hpf}$ confirmed these findings as $\mathrm{GFP}^{+} / \mathrm{RFP}^{+}$Schwann cells were observed along motor nerves (Fig. 2A). At this stage, not all nerve-associated Schwann cells had Notch reporter activity, and by $72 \mathrm{hpf}$, we rarely observed GFP ${ }^{+}$ Schwann cells (Fig. $2 B-D$ ).

Notch signaling has also been reported in secondary motor axons (Yeo et al., 2007). To confirm this expression, $\operatorname{Tg}(\operatorname{sox} 10$ : $m r f p$ ); $\operatorname{Tg}($ her4:egfp) embryos were labeled with an antibody to acetylated tubulin. Between 24 and $38 \mathrm{hpf}$, Notch activity was observed in motor axons in the periphery (Fig. 2E,F). However, by $54 \mathrm{hpf}$, we observed no $\mathrm{GFP}^{+}$motor axons (Fig. $2 G$ ). Interestingly, peripheral Notch activity observed between 54 and 72 hpf was reminiscent of perineurial glial morphology at these developmental stages (Fig. 2D, $H$ ).

From the previous data, we observe Notch activity exclusively in Schwann cells and motor axons before perineurial glia exit the CNS (Fig. 2A-H). However, between 48 and 72 hpf, Notch activity was maintained in the periphery in a pattern consistent with expression in perineurial glia (Fig. 2D, H) (Kucenas et al., 2008). To determine whether the peripheral Notch activity we observed was found in perineurial cells, we imaged $\operatorname{Tg}(n k x 2.2 a$ :egfp); $\operatorname{Tg}($ her4:drfp) larvae. At $48 \mathrm{hpf}$, all perineurial processes in the PNS were RFP ${ }^{+}$(Fig. 2J). Between 54 and 72 hpf, every GFP ${ }^{+}$ perineurial cell body in the PNS was also $\mathrm{RFP}^{+}$(Fig. 2K,L).

To independently confirm Notch activity in migrating perineurial glia, transverse sections of 48,54 , and $72 \mathrm{hpf}$ $\operatorname{Tg}(n k x 2.2 a: e g f p) ; \operatorname{Tg}(T p 1: m c h e r r y)$ larvae were labeled with a Sox10 antibody. At all ages, Sox $10^{+} / \mathrm{mCherry}^{-}$Schwann cells were observed along motor nerves (Fig. 2M-O). At 54 and $72 \mathrm{hpf}$, stages of active perineurial glial migration, all peripheral perineurial glia were $\mathrm{GFP}^{+} / \mathrm{mCherry}^{+} / \mathrm{Sox} 10^{-}$(Fig. $2 \mathrm{~N}, \mathrm{O}$ ). Although $\mathrm{mCherry}{ }^{+} / \mathrm{Sox} 10^{+}$Schwann cells were observed along peripheral motor nerves, they were rare, as the majority of Sox $10^{+}$cells lacked mCherry expression (Fig. 2M-O,Q).

Previous studies in Drosophila have demonstrated that Notch signaling is only active during peripheral glial migration and is quickly downregulated once the glia reach their final target (Edenfeld et al., 2007). To determine whether the window of Notch activity in zebrafish perineurial glia correlates with their active migration, we again used $\operatorname{Tg}(n k x 2.2 a: e g f p) ; \operatorname{Tg}($ her4: $d r f p)$ embryos. This Notch reporter line uses a PEST amino acid sequence that dramatically decreases the half-life of RFP within the cell, allowing us to accurately determine Notch signaling dynamics in perineurial glia. At $96 \mathrm{hpf}$, perineurial cells were $\mathrm{RFP}^{+}$, but expression of the transgene was lower than was seen at $72 \mathrm{hpf}$ (data not shown). By $6 \mathrm{dpf}$, we detected no $\mathrm{RFP}^{+}$cells along motor nerves, and this developmental stage coincides with the loss of migratory behaviors of perineurial glia. The data presented above demonstrate that Notch activity is observed in migratory perineurial glia and is downregulated when they cease their migration.

\section{Notch signaling is required for perineurial glial migration out of the CNS}

In Drosophila, disrupted Notch signaling leads to aberrant peripheral glial migration (Edenfeld et al., 2007). Glia also display more filopodia-like processes than seen in controls (Edenfeld et al., 2007). Because we observed Notch activity in perineurial glia during their migration, we hypothesized that Notch signaling may mediate their exit from the CNS in zebrafish. To test this idea, we interfered with the Notch pathway both pharmacologically and genetically and assayed their migration.

Previously, both DAPT, a common $\gamma$-secretase inhibitor that mediates the cleavage of the NICD, and the $T g(h s p: d n S u(H): g f p)$ transgenic line, which specifically impairs the Notch signaling cascade by producing a dominant-negative form of the NICD cofactor, $\mathrm{Su}(\mathrm{H})$, have been shown to effectively reduce Notch reporter line expression in zebrafish and impair Notch signaling (Parsons et al., 2009; Ninov et al., 2012). We similarly confirmed that our DAPT treatment regimen and heat-shock protocol effectively reduced Notch reporter line expression (Fig. 2P). Additionally, DAPT has been shown to phenocopy Notch signaling mutants in zebrafish (Geling et al., 2002). Therefore, we were confident that manipulating the Notch pathway with these tools would impair Notch signaling and allow us to assay the role of Notch in perineurial migration.

As a first step, $\operatorname{Tg}(n k x 2.2 a: e g f p) ; \operatorname{Tg}($ sox10:mrfp) larvae were treated with DAPT starting at $40 \mathrm{hpf}$, before perineurial glia exit the spinal cord. In vivo time-lapse imaging from 48 to $68 \mathrm{hpf}$ revealed that unlike control larvae (Fig. 1, Movie 1), perineurial cell bodies in DAPT-treated larvae $(n=19)$ never exited the CNS (Fig. 3, Movie 2). Instead, perineurial cells extended extensive filopodia-like processes out of MEPs next to migrating Schwann cells (Fig. 3, Movie 2). These processes were significantly more protrusive than those seen in controls and had a fan-like appearance that often branched and dynamically extended and retracted (Figs. 1, 3, Movies 1, 2). From these data we conclude that Notch signaling is required for perineurial glial migration from the spinal cord.

To determine whether Notch signaling is necessary to maintain perineurial migration once they exit the spinal cord, we treated $\operatorname{Tg}(n k x 2.2 a: e g f p)$ larvae with DAPT at different stages and assayed perineurial occupation of nerves with in vivo imaging. At $64 \mathrm{hpf}, \mathrm{GFP}^{+}$perineurial glia in control larvae $(n=17)$ had exited into the periphery and were observed in an iterated pattern along the anterior-posterior axis of the larvae (Fig. 4A). In contrast, $\mathrm{GFP}^{+}$perineurial glial cell bodies in larvae treated with DAPT from 40 to $64 \operatorname{hpf}(n=60)$ failed to exit the spinal cord, and this is consistent with data presented above (Figs. 3, 4B). To verify our DAPT results and specifically confirm the role of Notch in perineurial glial migration, $\operatorname{Tg}(n k x 2.2 a: e g f p) ; \operatorname{Tg}(h s p: d n S u(H)$ : $g f p)$ larvae were heat shocked at $36 \mathrm{hpf}(n=18)$. At $64 \mathrm{hpf}$, no perineurial cell bodies had exited into the periphery (Fig. 4C). Instead, perineurial processes similar to those observed in DAPTtreated larvae were present (Fig. 4C). In $84 \mathrm{hpf}$ control larvae $(n=19), \mathrm{GFP}^{+}$perineurial glia migrated further into the periphery and occupied both dorsal and ventral motor nerve roots (Fig. $4 D)$. Interestingly, when $\operatorname{Tg}(n k x 2.2 a: e g f p)$ larvae were treated with DAPT from 60 to $84 \mathrm{hpf}(n=60)$ or heat shocked at $56 \mathrm{hpf}$ $(n=24)$, after perineurial glia initiated their migration from the 

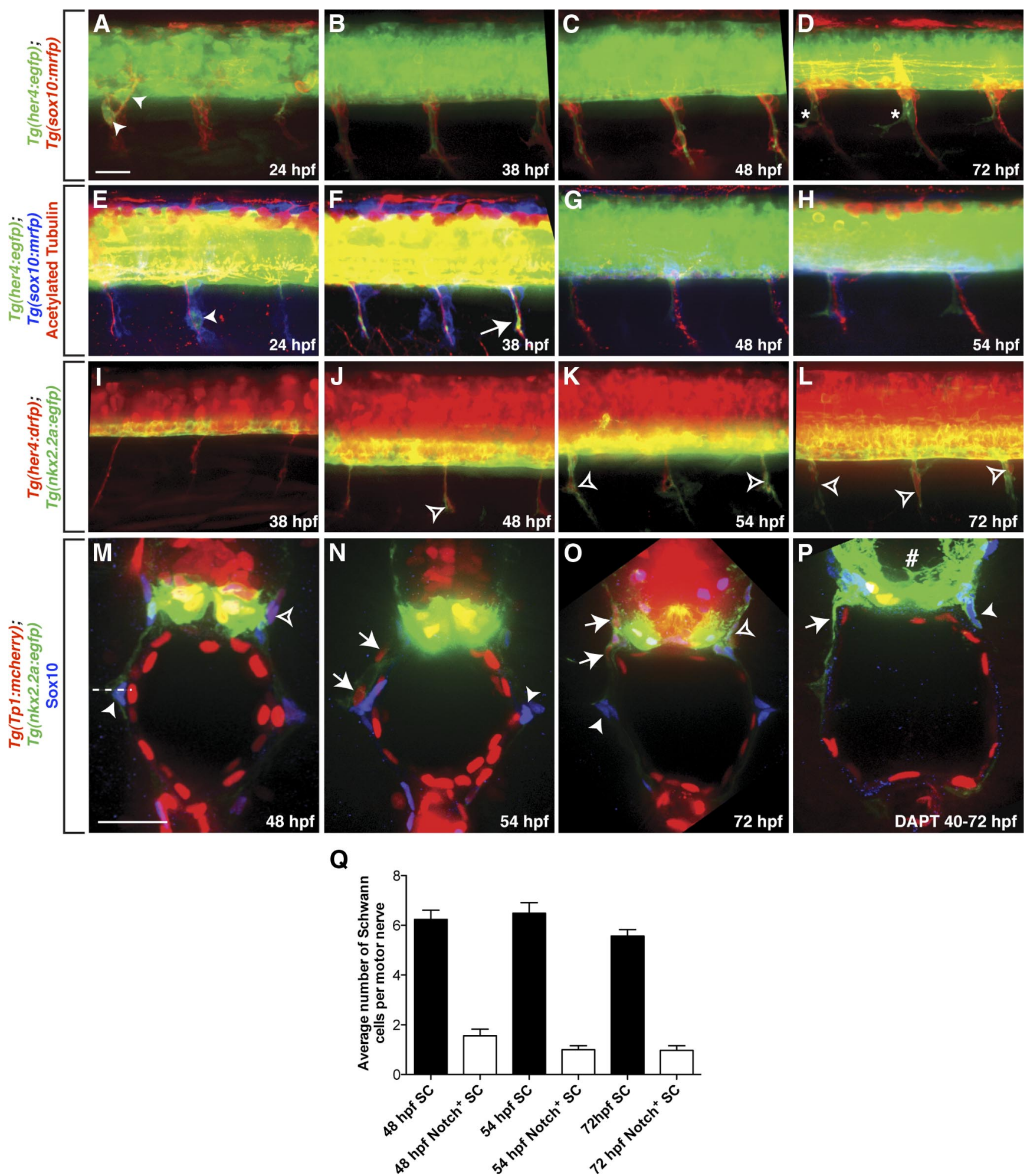

Figure 2. $\quad \boldsymbol{A}-\boldsymbol{D}, \ln \operatorname{Tg}\left(\right.$ sox 10:mrfp); $\operatorname{Tg}\left(\right.$ her4:egfp) larvae, some RFP ${ }^{+}$Schwann cell precursors along peripheral motor nerves were GFP ${ }^{+}$(arrowheads) at 24 hpf $(\boldsymbol{A})$, but not between 38 and 72 hpf $(\boldsymbol{B}-\boldsymbol{D})$. D, At 72 hpf, Notch activity (asterisk) appeared in a pattern consistent with perineurial glial morphology. $\boldsymbol{E}-\boldsymbol{H}$, Notch activity was detected in Schwann cells and secondary motor axons

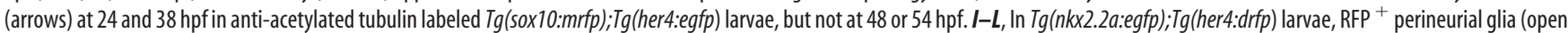

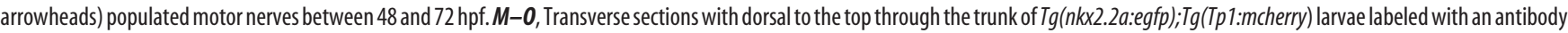
specific to Sox10 (blue). At all stages, the majority of Schwann cells (arrowhead) were $\mathrm{mCherry}{ }^{-}$. mCherry ${ }^{+}$Schwann cells (open arrowheads) were rarely seen. In contrast, at 48 and $72 \mathrm{hpf}$, all perineurial glia (arrows) were $\mathrm{mCherry}{ }^{+} . P$, When $T g(n k x 2.2 a: e g f p) ; T g(T p 1: m c h e r r y)$ larvae were treated with DAPT from 40 to 72 hpf, reporter line expression of mCherry was significantly reduced in the spinal cord (number sign). In these larvae, GFP ${ }^{+}$perineurial glial processes (arrow) were observed as well as Sox $10^{+}$Schwann cells (arrowhead). $\mathbf{Q}$, Quantification of Sox $10^{+} / \mathrm{mCherry}{ }^{+}$ vs $S_{0 \times 10^{+}} / \mathrm{mCherry}{ }^{-}$Schwann cells (SC) along ventral motor roots to the horizontal myoseptum (horizontal dashed line). $\boldsymbol{A}-\boldsymbol{L}$, Lateral views of the spinal cord with dorsal to the top and anterior to the left. Scale bars: $A-L, 50 \mu \mathrm{m} ; \boldsymbol{M}-\mathbf{0}, 25 \mu \mathrm{m}$. 


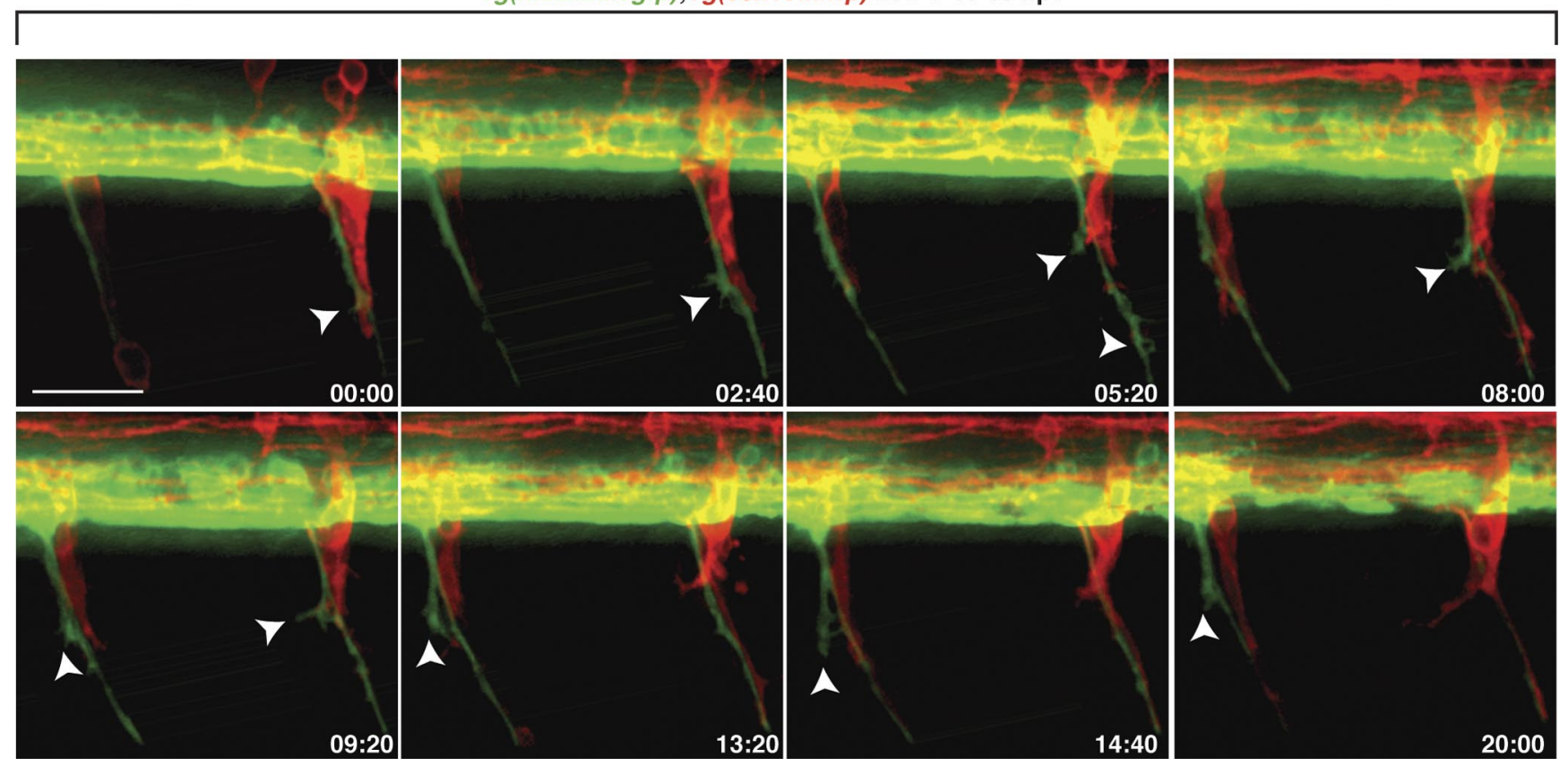

Figure 3. Notch signaling is required for perineurial glial migration out of the spinal cord. Frames captured from a $20 \mathrm{~h}$ time-lapse movie of a DAPT-treated $\operatorname{Tg}(\mathrm{nkx2.2a:egfp);Tg(s0x10:mrfp)} \mathrm{larva}$ beginning at $48 \mathrm{hpf}$. Numbers in lower right corners denote time elapsed from the first frame of the figure. At $\sim 50 \mathrm{hpf}\left(00: 00\right.$ time point), GFP ${ }^{+}$perineurial processes (arrowhead) extended into the CNS at MEPs immediately next to Schwann cells (red). Over the time sequence, perineurial cell bodies never exited the spinal cord. Instead, their membrane protrusions got progressively more filamentous (arrowheads). Images are lateral views of the spinal cord with dorsal to the top and anterior to the left. Scale bar, $50 \mu \mathrm{m}$.

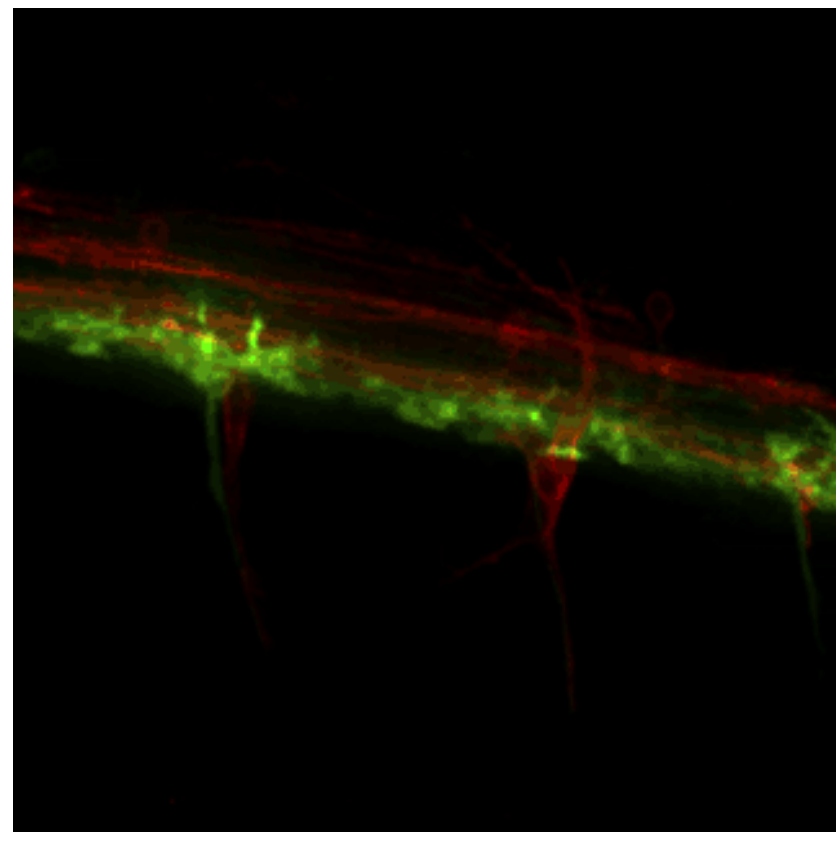

Movie 2. Notch signaling is required for perineurial glial exit from the CNS. In the absence of Notch signaling, perineurial glia fail to migrate out of the spinal cord and, instead, display extremely protrusive membrane processes.

$\mathrm{CNS}, \mathrm{GFP}^{+}$cells were associated with ventral motor nerves in the PNS and were indistinguishable from control larvae (Fig. 4E,F). The only difference we observed was the lack of dorsal motor axon-associated perineurial cells (Fig. 4E,F). Together, these results demonstrate that perineurial glia only require Notch for their initial migration from the spinal cord. Notch perturbation after they exit the CNS does not affect the extent or speed that they migrate along nerves.
To determine whether the perineurial glial migration defect could be rescued at later stages by relieving Notch signaling inhibition, $\operatorname{Tg}(n k \times 2.2 a$ :egfp $)$ larvae were treated with DAPT or heat shocked early (40-64 hpf, DAPT; 36 hpf, heat shock) or late (60-84 hpf, DAPT; $56 \mathrm{hpf}$, heat shock), and allowed to recover until $100 \mathrm{hpf}$. In control larvae at this stage $(n=13), \mathrm{GFP}^{+}$ perineurial glia were associated with both dorsal and ventral motor nerve branches and had begun to extend along axon subbranches in the periphery (Fig. 4G). In larvae that had Notch inhibition early (DAPT $n=60$, heat shock $n=18$ ), $\mathrm{GFP}^{+}$ perineurial glial cell bodies never migrated into the PNS (Fig. $4 H, I$ ). Only membrane processes were seen exiting at MEPs (Fig. $4 H, I)$. In these larvae, we also observed significant CNS defects, which are consistent with the previously reported role of the Notch signaling cascade in nervous system patterning (Park et al.,, 2005; Shin et al., 2007). In larvae that had Notch inhibition late (DAPT $n=60$, heat shock $n=24), \mathrm{GFP}^{+}$perineurial glial cell bodies were associated with both dorsal and ventral motor nerve roots, like those seen in control larvae (Fig. 4J-L). However, we observed breaks in the perineurial chains, suggesting that perineurial glia were not differentiating even though their migration appeared normal (Fig. $4 K, L$ ). Together, from these results we conclude that Notch signaling is required to initiate, but not maintain, perineurial glial migration. Additionally, relieving Notch inhibition does not rescue the early migration phenotype, demonstrating that Notch promotes perineurial exit from the CNS during a discrete temporal window.

To further verify that the results we observed with DAPT were specific to perturbation of the Notch signaling cascade, $T g(n k x 2.2 a: e g f p) ; T g(h s p: G a l 4) ; T g(U A S:$ Notch1a-intra) larvae were heat shocked at $36 \mathrm{hpf}$ to induce expression of a constitutively active form of NICD and then treated with DAPT from 36 to $72 \mathrm{hpf}(n=32)$. In control larvae $(n=32), \mathrm{GFP}^{+}$perineurial glia migrated normally into the periphery and were associated 


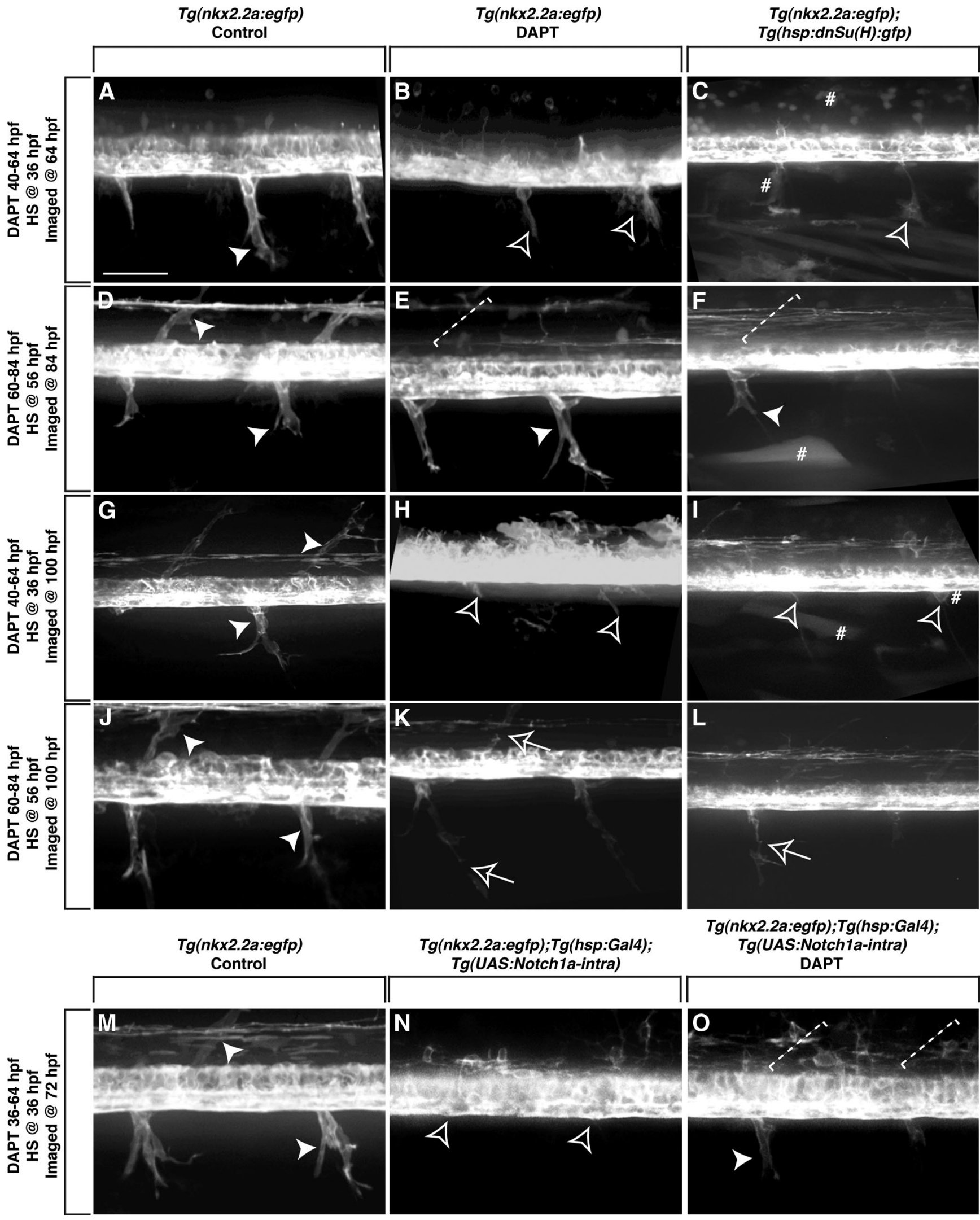

Figure 4. Notch is required during distinct stages of perineurial glial development. Lateral views of the spinal cord with dorsal to the top and anterior to the left of $\operatorname{Tg}(n k x 2.2 a: e g f p)(\boldsymbol{A}, \boldsymbol{B}, \boldsymbol{D}, \boldsymbol{E}$,

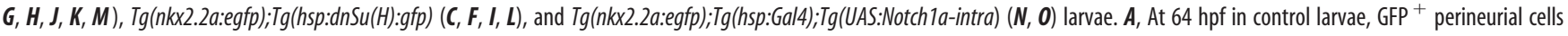
(arrowhead) migrated into the PNS. In contrast, in larvae treated with DAPT from 40 to $64 \mathrm{hpf}(\boldsymbol{B})$ or heat shocked at $36 \mathrm{hpf}(\boldsymbol{C})$, perineurial cells failed to exit the CNS. Instead, only highly protrusive processes were detected (open arrowhead). $\boldsymbol{D}$, By $84 \mathrm{hpf}, \mathrm{GFP}^{+}$perineurial cells in control larvae populated both ventral and dorsal motor nerve braches. $\boldsymbol{E}, \boldsymbol{F}$, In contrast, in larvae treated with DAPT from 60 to $84 \mathrm{hpf}(\boldsymbol{E})$ or heat shocked at $56 \mathrm{hpf}(\boldsymbol{F}), \mathrm{GFP}^{+}$perineurial cells only appeared to migrate along ventral motor nerves and were missing dorsally (dashed bracket). $\boldsymbol{G}, \mathrm{In} 100 \mathrm{hpf}$ control larvae, GFP ${ }^{+}$perineurial cells were found on dorsal and ventral motor nerves. $\boldsymbol{H}, \boldsymbol{I}$, In larvae treated with DAPT from 40 to $64 \mathrm{hpf}(\boldsymbol{H})$ or heat shocked at $36 \mathrm{hpf}(\boldsymbol{I})$ and $($ Figure legend continues.) 
with both dorsal and ventral motor nerves (Fig. 4M). When larvae were heat shocked and treated with DAPT, we observed a partial rescue of the perineurial glial migration defect (Fig. 4O). GFP ${ }^{+}$Perineurial cells were observed along ventral motor nerves, but not along dorsal branches (Fig. 4O). Additionally, not only was an excess number of oligodendrocyte progenitor cells (OPCs) observed in the CNS in $T g(n k x 2.2 a$ :egfp); $\operatorname{Tg}$ (hsp:Gal4); $\operatorname{Tg}$ (UAS:Notch1a-intra) larvae, which is consistent with the previously described findings that unregulated Notch signaling promotes CNS glial formation (Fig. $4 N$ ), but the original DAPT-induced loss of OPCs was also rescued by inducing a constitutively active form of Notch (Fig. 4O) (Snyder et al., 2012). Intriguingly, when larvae were only heat shocked $(n=32)$ and allowed to develop until $72 \mathrm{hpf}, \mathrm{GFP}^{+}$ perineurial glia rarely exited the CNS (Fig. $4 N)$. These findings, together with the previous experiments, suggest that there is not only a temporal dependence for Notch during perineurial glial migration, but also a requirement for the precise control of Notch expression levels as well.

\section{Perineurial glial differentiation is notch dependent}

Above, we show that impairing Notch signaling in perineurial glial cells after they initiate their migration causes breaks in perineurial chains, which we hypothesize might be due to their inability to differentiate into the mature perineurium. These data, in conjunction with studies that have previously shown Notch to play important roles in Schwann cell differentiation (Mirsky et al., 2008; Woodhoo et al., 2009), led us to hypothesize that Notch might similarly mediate aspects of perineurial differentiation. To investigate this, we molecularly assayed perineurial differentiation in larvae with Notch inhibition.

Tight junctions are a unique hallmark of the perineurium along peripheral nerves (Bourne, 1968; Kristensson and Olsson, 1971; Akert et al., 1976). Studies in rodents have demonstrated that perineurial tight junctions are only observed in older animals at stages when injected dyes are unable to penetrate nerves, suggest-

$\leftarrow$

(Figurelegend continued.) allowed to recover until $100 \mathrm{hpf}$, perineurial processes but not cell bodies were seen in the periphery. $\boldsymbol{K}, \boldsymbol{L}$, In contrast, in larvae treated with DAPT from 60 to $84 \mathrm{hpf}(\boldsymbol{K})$ or heat shocked at $56 \mathrm{hpf}(\boldsymbol{L})$ and allowed to recover until $100 \mathrm{hpf}, \mathrm{GFP}^{+}$perineurial cells were associated with peripheral motor nerves in discontinuous chains (arrows), which was never observed in controls $(J)$ (arrowheads). $\boldsymbol{M}, \boldsymbol{N}$, When compared with control larvae at $72 \mathrm{hpf}(\boldsymbol{M})$, heat shock induction of a constitutively active form of the Notch intracellular domain at $36 \mathrm{hpf}(\boldsymbol{N})$ resulted in a failure of perineurial glial migration into the periphery. $\mathbf{0}$, When treated with DAPT and heat shocked at $36 \mathrm{hpf}$, partial rescue of the perineurial glial migration phenotype was observed at $72 \mathrm{hpf}$. Number sign denotes examples of GFP ${ }^{+}$cells due to heat shock. Scale bar, $50 \mu \mathrm{m}$.

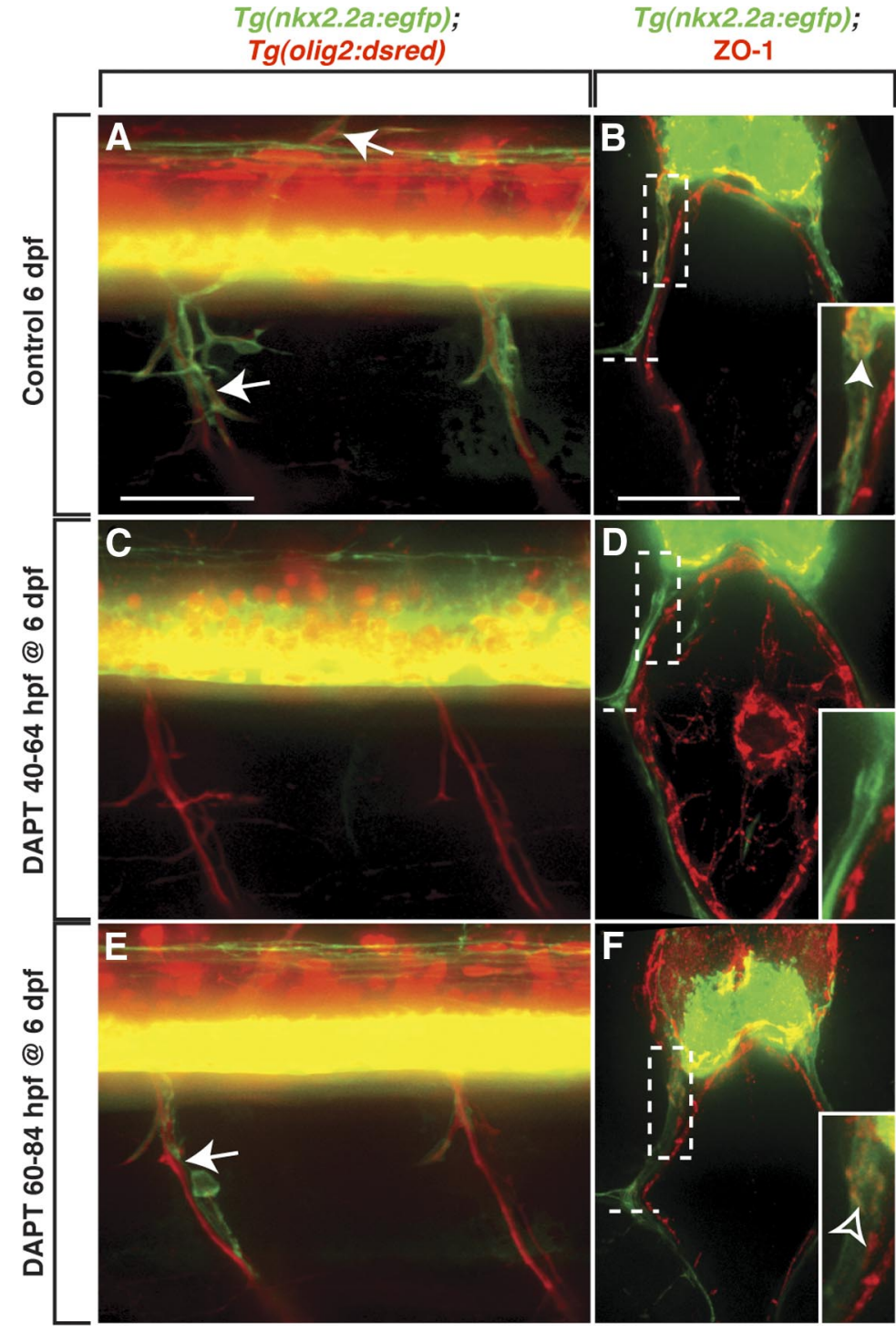

Figure 5. Notch signaling is required for perineurial glial differentiation. $A, C, E$, Lateral views of the spinal cord with dorsal to the top and anterior to the left of $\operatorname{Tg}($ (nkx2.2a:egfp); $\mathrm{Tg}($ olig2:dsred) larvae at $6 \mathrm{dpf} . \boldsymbol{B}, \boldsymbol{D}, \boldsymbol{F}$, Transverse sections with dorsal to the top through the trunk of $6 \mathrm{dpf} \operatorname{Tg}(n k \times 2.2 a$ :egfp) larvae labeled with an antibody specific to ZO-1 (red). $A$, In control larvae, GFP ${ }^{+}$perineurial cells (arrows) ensheathed dorsal and ventral motor nerves. $\boldsymbol{B}$, Within these perineurial cells, high levels of ${\mathrm{ZO}-1^{+}}^{+}$tight junctions (arrowhead) were detected extending from the ventral spinal cord to the horizontal myoseptum (dashed line). $\boldsymbol{C}, \boldsymbol{D}$, In contrast, when larvae were treated with DAPT from 40 to $64 \mathrm{hpf}$ and left to recover until $6 \mathrm{dpf}$, perineurial glial processes but not cell bodies migrated into the periphery and no $\mathrm{ZO}-1^{+}$tight junctions were detected. $\boldsymbol{E}$, In larvae treated from 60 to $84 \mathrm{hpf}$ and allowed to recover until $6 \mathrm{dpf}, \mathrm{GFP}^{+}$perineurial cells migrated along motor nerves, but not in continuous chains (arrow). $\boldsymbol{F}$, In this instance, $\mathrm{ZO}-1^{+}$tight junctions were observed in perineurial cells most proximal to the ventral spinal cord, but never further along the nerve. $\boldsymbol{B}, \boldsymbol{D}, \boldsymbol{F}$, Insets show magnified view of the dashed rectangular regions. Scale bars: $A, C, E, 50 \mu \mathrm{m} ; \boldsymbol{B}, \boldsymbol{D}, \boldsymbol{F}, 25 \mu \mathrm{m}$.

ing that perineurial cell differentiation is correlated to tight junction presence (Kristensson and Olsson, 1971). To determine the extent of perineurial differentiation in control and DAPT-treated larvae, we labeled tissue with an antibody to ZO-1. In control $\operatorname{Tg}\left(n k x 2.2 a\right.$ :egfp); $\operatorname{Tg}$ (olig2:dsred) larvae at $6 \mathrm{dpf}(n=21), \mathrm{GFP}^{+}$ perineurial cells ensheathed the main trunk of motor nerves as well as axons that had branched off of the main root (Fig. 5A). When these larvae were sectioned and labeled with an anti-ZO-1 antibody, high levels of tight junctions were observed within the $\mathrm{GFP}^{+}$perineurial cells along the ventral motor nerves (Fig. $5 B$ ). The highest ZO-1 levels were detected in perineurial glia most proximal to the ventral spinal cord, but were also found in perineurial cells found at and beyond the horizontal myoseptum, 

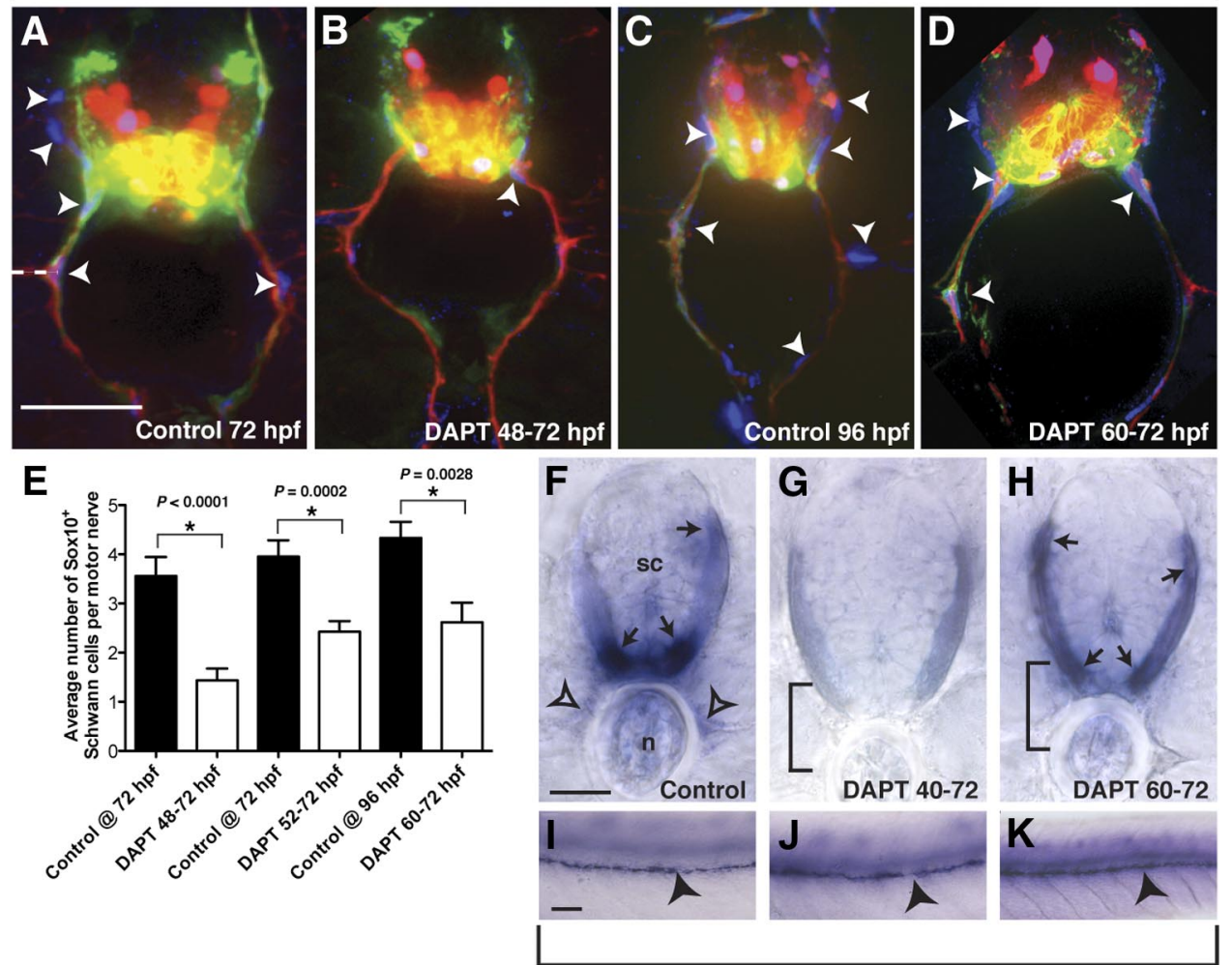

myelin basic protein

Figure 6. Perturbed perineurial glial development influences Schwann cell development. $\boldsymbol{A}-\boldsymbol{D}$, Transverse sections with dorsal to the top through the trunk of $\operatorname{Tg}(n k x 2.2 a:$ :egfp); $\operatorname{Tg}($ olig2:dsred) larvae labeled with an antibody specific to Sox10 (blue). $\boldsymbol{F}-\boldsymbol{K}$, Transverse $(\boldsymbol{F}-\boldsymbol{H})$ and whole-mount $(\boldsymbol{I}-\boldsymbol{K})$ views with dorsal to the top of $m b p$ expression in $96 \mathrm{hpflarvae.} \boldsymbol{A}-\boldsymbol{D}$, Compared with controls, DAPT-treated larvae had significantly fewer Schwann cells (arrowheads) populating the motor nerve. $\boldsymbol{E}$, Quantification of Sox $10^{+}$cells along ventral motor roots to the horizontal myoseptum. $\boldsymbol{F}$, I, In control larvae, mbp transcript was detected in oligodendrocytes in the CNS (arrows) as well as in Schwann cells along motor nerves (open arrowheads) and the PLLn (arrowheads). G, J, In contrast, larvae treated with DAPT from 40 to $72 \mathrm{hpf}$ showed strongly reduced mbp expression in the CNS and no detectable expression along motor nerves. However, PLLn expression was indistinguishable from controls. $\boldsymbol{H}, \boldsymbol{K}$, Similar to the early DAPT treatment, larvae exposed to DAPT from 60 to $72 \mathrm{hpf}$ showed no motor nerve mbp expression, but indistinguishable expression in the CNS and along the PLLn. Statistical significance was determined using the unpaired $t$ test. $p$-values are shown for each treatment type compared with controls. Horizontal dashed line denotes horizontal myoseptum. Scale bars: A-D, $25 \mu \mathrm{m} ; \boldsymbol{F}-\boldsymbol{H}, 25 \mu \mathrm{m} ; \boldsymbol{I}-\boldsymbol{K}, 50 \mu \mathrm{m}$.

a connective tissue partition of the myotome that separates dorsal and ventral body wall muscle masses (Fig. 5B). In contrast, in 6 dpf larvae treated with DAPT from 40 to $64 \mathrm{hpf}(n=39)$, $\mathrm{GFP}^{+}$ perineurial cell bodies were not observed in the periphery at $6 \mathrm{dpf}$ (Fig. 5C). Not unexpectedly, we never observed perineurial tight junctions in these larvae (Fig. 5D). Larvae treated with DAPT from 60 to $84 \mathrm{hpf}(n=42)$ had nerves occupied with individually spaced perineurial glia at $6 \mathrm{dpf}$ (Fig. 5E). Low levels of tight junctions were observed in perineurial cells most proximal to the ventral spinal cord in these larvae, but rarely detected further distally along the nerve (Fig. $5 F$ ). Together, these data are consistent with the hypothesis that Notch signaling is essential for perineurial glial differentiation. Interestingly, the affect on differentiation was observed almost $3 \mathrm{~d}$ after Notch inhibition was relieved, suggesting that like migration, perineurial differentiation is dependent on a narrow window of Notch activity.

\section{Perineurial glia direct Schwann cell development}

Previous studies have demonstrated that interactions between Schwann cells and perineurial glia along peripheral nerves are required to coordinate glial differentiation (Mirsky et al., 1999; Parmantier et al., 1999; Kucenas et al., 2008, 2009; Küspert et al., 2012). However, in all of these instances, the effect of Schwann cells on perineurial cells was assayed (Mirsky et al., 1999; Parmantier et al., 1999; Kucenas et al., 2008, 2009; Küspert et al., 2012). When the reciprocal interaction was investigated, perineurial specification was blocked and more specific information about the nature of perineurial influence on Schwann cells could not be determined (Kucenas et al., 2008). By impairing Notch signaling during distinct developmental stages, we can now further investigate the necessity of perineurial migration or differentiation on Schwann cell development.

To assay Schwann cells along motor nerves in DAPT-treated larvae, we labeled transverse sections of $\operatorname{Tg}(n k x 2.2 a$ :egfp); $\operatorname{Tg}$ (olig2:dsred) larvae at either 72 or $96 \mathrm{hpf}$ with an antibody to Sox10. In control larvae at both 72 and $96 \mathrm{hpf}(n=11$ and 17 larvae, 10 sections per larva), Sox $10^{+}$Schwann cells were associated with both ventral and dorsal branches of peripheral motor nerves (Fig. $6 A, C)$. In each DAPT treatment group ( $48-72 \mathrm{hpf}$, 52-72 hpf, and 60-72 hpf, $n=15$ larvae, 10 sections per larva), significantly fewer Sox $10^{+}$Schwann cells were observed along peripheral motor nerves (Fig. $6 B, D, E$ ). Interestingly, as the DAPT treatment windows covered less of the active migration phase of perineurial glia, we observed a less severe Schwann cell phenotype (Fig. $6 E$ ). From these data, we conclude that failure of 


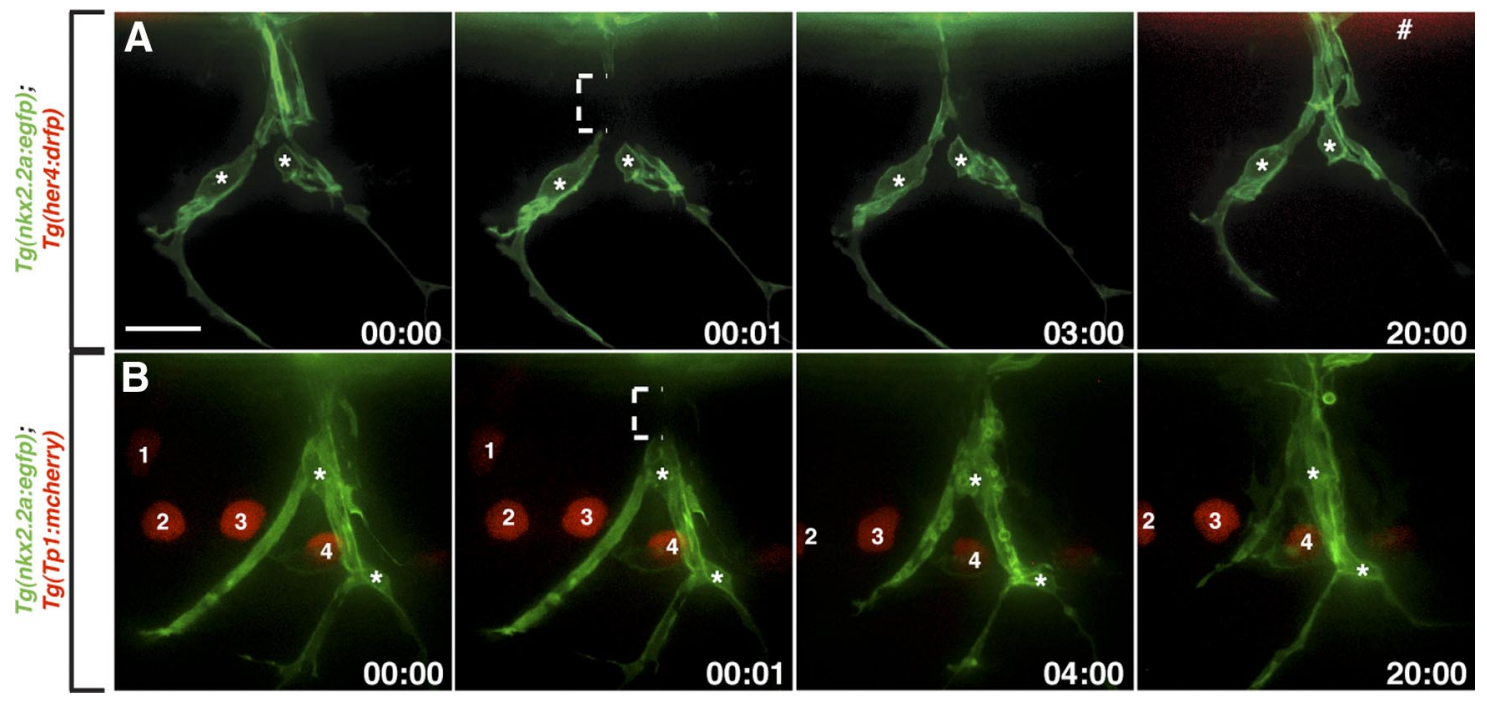

Figure 7. Notch activity is not detected in perineurial glia after injury. $\boldsymbol{A}, \boldsymbol{B}$, Images taken from a $\operatorname{Tg}(n k x 2.2 a: e g f p) ; \operatorname{Tg}($ her4:drfp) $(\boldsymbol{A})$ and $\operatorname{Tg}($ (nkx2.2a:egfp); $\operatorname{Tg}(\operatorname{Tp1}: \mathrm{mcherry})(\boldsymbol{B}) \operatorname{larva}$ after motor nerve injury beginning at $6 \mathrm{dpf}$. Numbers in lower right corners denote time elapsed from the first frame of the figure. $\boldsymbol{A}, \boldsymbol{B}$, Motor nerve-associated perineurial glia (asterisks) never express RFP or $\mathrm{mCherry}$ after nerve injury. $\boldsymbol{A}$, Number sign denotes RFP expression in the spinal cord. $\boldsymbol{B}, 1-4 \mathrm{mark} \mathrm{mCherry}{ }^{+}$cells in the periphery. Brackets show injury zones. All images are lateral views of a motor nerve with dorsal to the top and anterior to the left. Scale bar, $10 \mu \mathrm{m}$.

perineurial migration from the CNS directly affects the number of Schwann cells that occupy motor nerves.

Although we observed fewer Sox $10^{+}$Schwann cells associated with peripheral motor nerves in DAPT-treated larvae, they appeared to have migrated to the same extent as those in control larvae (Fig. $6 A-D$ ). Therefore, we investigated whether these Schwann cells were terminally differentiating. To do this, mRNA expression of myelin basic protein ( $\mathrm{mbp}$ ) was assayed in $96 \mathrm{hpf}$ control or DAPT-treated larvae. In control larvae $(n=11), m b p$ expression was detected in oligodendrocytes in the white matter of the spinal cord, as well as in Schwann cells associated with peripheral motor nerves and the PLLn (Fig. 6F,I). In contrast, when larvae were treated with DAPT from 40 to $72 \mathrm{hpf}(n=31)$, we observed reduced levels of $m b p$ in the spinal cord, which is consistent with previous reports demonstrating a role for Notch signaling in oligodendrocyte specification (Park and Appel, 2003; Park et al., 2005). We also did not detect $m b p$ expression along motor nerves (Fig. $6 G$ ). However, $m b p$ transcripts along the PLLn were observed in a pattern indistinguishable from control larvae, demonstrating that perturbing Notch signaling did not directly disrupt Schwann cell differentiation (Fig. $6 J$ ). In larvae that were treated with DAPT from 60 to $72 \mathrm{hpf}(n=16), m b p$ was detected in the white matter of the spinal cord and along the PLLn, but not along peripheral motor nerves (Fig. $6 \mathrm{H}, \mathrm{K}$ ). The above Schwann cell phenotypes were also confirmed using heat-shocked $T g$ (hsp: $d n S u(H): g f p$ ) larvae (data not shown). From these data, we conclude that Schwann cell number and differentiation are intimately tied to perineurial cell migration and differentiation.

\section{Notch activity is not observed in perineurial glia after injury}

Above, we have shown that perineurial glia require Notch signaling for their migration and differentiation during development. However, it is not known whether perineurial glia use Notch signaling after injury. Both Schwann cells and perineurial cells have been described as being integral players in peripheral regeneration. After injury, mature Schwann cells trans-differentiate into a progenitor-like state, shed their myelin sheaths, proliferate, migrate, and are integral for axon regrowth across the injury site (Geuna et al., 2009; Parrinello et al., 2010; Napoli et al., 2012).
Although far less studied, in vitro studies have described perineurial cells as the first cellular component to traverse the injury zone (Schroder et al., 1993). Additionally, at intermediate stages of peripheral regeneration, perineurial mini-fascicles have been observed in both the proximal and distal portions of the regenerating nerve, a phenomenon not observed along uninjured nerves (Geuna et al., 2009). These behaviors, coupled with the role of Notch during perineurial development described above, led us to hypothesize that Notch may be reactivated by perineurial glia after injury. To investigate this hypothesis, we injured motor nerves in 6-d-old $\operatorname{Tg}(n k x 2.2 a$ :egfp); $\operatorname{Tg}($ her4: $d r f p)(n=3)$ and $\operatorname{Tg}(n k \times 2.2 a$ :egfp); $\operatorname{Tg}(T p 1: m c h e r r y)(n=5)$ larvae and assayed Notch expression in perineurial cells. Surprisingly, in vivo imaging following injuries revealed that Notch activity was not detected in perineurial glia along injured motor nerves (Fig. 7). However, expression of both of these reporter lines was seen in other tissues (Fig. 7A,B). Because the injuries were complete transections that resulted in degeneration of distal stump axons and a Schwann cell response (data not shown), we would expect Notch activity used by perineurial glia during the regenerative process to be evident if it was present. These data demonstrate that perineurial glia use Notch signaling during nerve development, but not regeneration, raising the intriguing possibility that different mechanisms mediate glial behaviors during development and following injury.

\section{Discussion}

Novel roles for Notch during perineurial glial development During PNS development, peripheral glia migrate extensively to ensure full ensheathment of motor and sensory nerves. One class of peripheral glia, perineurial glia, are specified from precursors in the ventral spinal cord and migrate into the periphery via MEPs behind pioneering motor axons. Once in the PNS, they reciprocally interact with nerve-associated Schwann cells and ultimately differentiate into the mature perineurium. Very little work has investigated the mechanisms that mediate peripheral glial migration, and what we do know is strictly limited to the Schwann cell lineage (Jessen and Mirsky, 2005; Lyons et al., 2005; Newbern and Birchmeier, 2010). We describe here the first 
mechanism that is required to initiate perineurial glial migration from the CNS during development. Interestingly, when the Notch pathway is inhibited or overactive, as evidenced by our DAPT and constitutively active NICD experiments, perineurial glia rarely exit the CNS. This suggests that a complex mechanism of tight temporal and expression control of the Notch cascade is required for perineurial glial migration.

A possible alternate interpretation of our results could be that Notch inhibition leads to a failure of perineurial glial specification, which is why we never observe perineurial cell bodies in the PNS in experimental larvae. However, blocking perineurial glial specification in zebrafish causes ectopic motor axon exit from the CNS (Kucenas et al., 2008), and motor axon exit in our Notchimpaired larvae is unaffected (data not shown). Therefore, we are confident that Notch signaling is essential for perineurial migration and does not affect their specification from ventral spinal cord precursors.

In addition to the role of Notch signaling in perineurial glial migration, we describe a second, later role in perineurial differentiation. Currently, the only way we have to identify mature perineurial cells is by assaying their ability to form tight junctions with each other. This hallmark of the perineurium is well characterized, and studies in rodents have demonstrated that nerves in young animals have very low levels of perineurial tight junctions, while adults nerves have significantly more (Burkel, 1967; Kristensson and Olsson, 1971; Parmantier et al., 1999). Therefore, not only are tight junctions considered a sign of perineurial differentiation, but their relative levels can also be used to interpret the extent to which this structure has matured. When Notch signaling was impaired during the onset of perineurial differentiation, we observed significantly fewer tight junctions within the perineurial sheath. These data show that perineurial glia in Notch-depleted larvae are not differentiating into a mature blood-nerve barrier and illustrate the need to further investigate the mechanisms that control the development and maintenance of this essential nervous system component.

\section{Schwann cell development requires perineurial glia}

Previous studies have demonstrated that genetically removing perineurial glia early in development leads to severe Schwann cell defects along motor nerves (Kucenas et al., 2009). By impairing Notch signaling in perineurial cells, we were able to investigate whether perineurial cells are important during later stages of Schwann cell development. Interestingly, we saw Schwann cell defects when either perineurial migration or differentiation were perturbed, demonstrating that perineurial glia interact with Schwann cells at multiple stages of nerve assembly. These data open up the possibility that perineurial glia may be influencing Schwann cell survival and myelin maintenance later in life and lead us to question whether defects in perineurial cells contribute to peripheral myelinopathies.

We are confident, however, that the Schwann cell phenotypes we observed are not due to a direct role of Notch in this population. During the stages that Notch signaling was impaired, we rarely observed Schwann cells with active Notch signaling (Fig. $2 P$ ). Additionally, the reduced number of Schwann cells was not due to a proliferation defect as Schwann cells were observed dividing along peripheral motor nerves in DAPT-treated larvae (Movie 2), and we observed normal numbers of Schwann cells along the PLLn (data not shown). Furthermore, although we observed severely reduced $m b p$ expression along motor nerves in Notch-impaired larvae, PLLn $m b p$ expression was indistinguishable from that of control larvae, demonstrating that Schwann cell differentiation was not directly impaired. From these studies, we conclude that perturbed Notch activity directly affects perineurial glial development, which in turn, causes Schwann cell defects.

\section{Notch signaling is not used by perineurial glia after injury}

Perineurial cells play important roles during nerve assembly and have been implicated in regeneration as well (Schroder et al., 1993; Kucenas et al., 2008; Geuna et al., 2009; Parrinello et al., 2010). Therefore, we hypothesized that they may use Notch signaling after nerve injury. To investigate this theory, we performed complete motor nerve transections on 6-d-old larvae. Interestingly, perineurial cells never reactivated Notch signaling after injury. This finding could mean several things. First, it might suggest that perineurial cells do not play any role during regeneration. However, published studies both in vivo and in vitro suggest this is not the case, and our own unpublished data corroborate these findings (Schroder et al., 1993; Parrinello et al., 2010). Second, the possibility exists that the Notch reporter lines we were using are not an accurate readout of the type of Notch signaling being used or are not sensitive enough to detect activated Notch signaling after nerve transection. Finally, it's possible that perineurial cells play a role after injury, but that Notch signaling does not mediate these events. This is an intriguing possibility because it suggests that the cellular mechanisms that mediate regeneration of the PNS are not simply a recapitulation of developmental events. The most obvious next experiment would be to perturb Notch signaling in perineurial cells before or during an injury to assay whether these cells require this signaling cascade during regeneration. We have attempted to do this with both DAPT and the $T g(h s p: d n S u(H): g f p)$ line. However, neither of these reagents has successfully reduced Notch reporter line expression in older larvae like we observed in younger animals. Therefore, we are not confident that the conclusions we would draw about perineurial behaviors could be attributed to impaired Notch signaling. Future experiments that allow for temporal, cell type-specific Notch inhibition in older larvae are essential to be able to address this question.

\section{Source of the Notch ligand}

In the above experiments, we demonstrate that Notch signaling is essential for perineurial development. However, the source of the Notch receptor ligand is unknown. We hypothesize that it could be coming from either motor axons or motor nerve-associated Schwann cells. At the late stages of development that we observe perineurial dependence on Notch, however, motor axons are no longer suspected of expressing the Notch ligand, Delta (Kim et al., 2008). Alternatively, Schwann cells represent an attractive source for a Notch ligand because after Raf-kinase upregulation in myelinating cells, which induces Schwann cells to transdifferentiate, Jagged 1 expression is increased sevenfold (Napoli et al., 2012). Therefore, we believe Schwann cells are an ideal potential source of Notch ligand for perineurial glia and are amenable to future experiments investigating this hypothesis.

In summary, our work describes a novel molecular mechanism that mediates perineurial glial migration and differentiation. Perturbing either of these events during development causes a failure in Schwann cell differentiation, and ultimately, nerve assembly. Our studies reinforce the need to investigate perineurial glia and their interactions with neighboring cell populations as defects in their development might contribute to diseases of nerve assembly, maintenance, or regeneration. In particular, peripheral myelinopathies may actually be the result of perturbed perineurial development or maintenance, and further studies in- 
vestigating the mechanisms that control their migration and differentiation are sure to shed light not only on the paradigms that build nervous systems, but also on those that become dysregulated during disease.

\section{References}

Akert K, Sandri C, Weibel ER, Peper K, Moor H (1976) The fine structure of the perineural endothelium. Cell Tissue Res 165:281-295. Medline

Andersson ER, Sandberg R, Lendahl U (2011) Notch signaling: simplicity in design, versatility in function. Development 138:3593-3612. CrossRef Medline

Banerjee S, Gordon L, Donn TM, Berti C, Moens CB, Burden SJ, Granato M (2011) A novel role for MuSK and non-canonical Wnt signaling during segmental neural crest cell migration. Development 138:3287-3296. CrossRef Medline

Bourne GH (1968) The structure and function of nervous tissue. New York: Academic.

Bray SJ (2006) Notch signalling: a simple pathway becomes complex. Nat Rev Mol Cell Biol 7:678-689. CrossRef Medline

Burkel WE (1967) The histological fine structure of perineurium. Anat Rec 158:177-189. CrossRef Medline

Edenfeld G, Altenhein B, Zierau A, Cleppien D, Krukkert K, Technau G, Klämbt C (2007) Notch and Numb are required for normal migration of peripheral glia in Drosophila. Dev Biol 301:27-37. CrossRef Medline

Geling A, Steiner H, Willem M, Bally-Cuif L, Haass C (2002) A gammasecretase inhibitor blocks Notch signaling in vivo and causes a severe neurogenic phenotype in zebrafish. EMBO Rep 3:688-694. CrossRef Medline

Geuna S, Raimondo S, Ronchi G, Di Scipio F, Tos P, Czaja K, Fornaro M (2009) Chapter 3: Histology of the peripheral nerve and changes occurring during nerve regeneration. Int Rev Neurobiol 87:27-46. CrossRef Medline

Gilmour DT, Maischein HM, Nüsslein-Volhard C (2002) Migration and function of a glial subtype in the vertebrate peripheral nervous system. Neuron 34:577-588. CrossRef Medline

Jessen KR, Mirsky R (2002) Signals that determine Schwann cell identity. J Anat 200:367-376. CrossRef Medline

Jessen KR, Mirsky R (2005) The origin and development of glial cells in peripheral nerves. Nat Rev Neurosci 6:671-682. CrossRef Medline

Kim H, Shin J, Kim S, Poling J, Park HC, Appel B (2008) Notch-regulated oligodendrocyte specification from radial glia in the spinal cord of zebrafish embryos. Dev Dyn 237:2081-2089. CrossRef Medline

Kimmel CB, Ballard WW, Kimmel SR, Ullmann B, Schilling TF (1995) Stages of embryonic development of the zebrafish. Dev Dyn 203:253-310. CrossRef Medline

Kirby BB, Takada N, Latimer AJ, Shin J, Carney TJ, Kelsh RN, Appel B (2006) In vivo time-lapse imaging shows dynamic oligodendrocyte progenitor behavior during zebrafish development. Nat Neurosci 9:1506-1511. CrossRef Medline

Kristensson K, Olsson Y (1971) The perineurium as a diffusion barrier to protein tracers. Differences between mature and immature animals. Acta Neuropathol 17:127-138. CrossRef Medline

Kucenas S, Takada N, Park HC, Woodruff E, Broadie K, Appel B (2008) CNS-derived glia ensheath peripheral nerves and mediate motor root development. Nat Neurosci 11:143-151. CrossRef Medline

Kucenas S, Wang WD, Knapik EW, Appel B (2009) A selective glial barrier at motor axon exit points prevents oligodendrocyte migration from the spinal cord. J Neurosci 29:15187-15194. CrossRef Medline

Küspert M, Weider M, Müller J, Hermans-Borgmeyer I, Meijer D, Wegner M (2012) Desert hedgehog links transcription factor Sox10 to perineurial development. J Neurosci 32:5472-5480. CrossRef Medline

Lyons DA, Pogoda HM, Voas MG, Woods IG, Diamond B, Nix R, Arana N, Jacobs J, Talbot WS (2005) erbb3 and erbb2 are essential for Schwann cell migration and myelination in zebrafish. Curr Biol 15:513-524. CrossRef Medline

Mirsky R, Parmantier E, McMahon AP, Jessen KR (1999) Schwann cell- derived desert hedgehog signals nerve sheath formation. Ann N Y Acad Sci 883:196-202. CrossRef Medline

Mirsky R, Woodhoo A, Parkinson DB, Arthur-Farraj P, Bhaskaran A, Jessen KR (2008) Novel signals controlling embryonic Schwann cell development, myelination and dedifferentiation. J Peripher Nerv Syst 13:122135. CrossRef Medline

Napoli I, Noon LA, Ribeiro S, Kerai AP, Parrinello S, Rosenberg LH, Collins MJ, Harrisingh MC, White IJ, Woodhoo A, Lloyd AC (2012) A central role for the ERK-signaling pathway in controlling Schwann cell plasticity and peripheral nerve regeneration in vivo. Neuron 73:729-742. CrossRef Medline

Newbern J, Birchmeier C (2010) Nrg1/ErbB signaling networks in Schwann cell development and myelination. Semin Cell Dev Biol 21:922-928. CrossRef Medline

Ninov N, Borius M, Stainier DYR (2012) Different levels of Notch signaling regulate quiescence, renewal and differentiation in pancreatic endocrine progenitors. Development 139:1557-1567. CrossRef Medline

Park HC, Appel B (2003) Delta-Notch signaling regulates oligodendrocyte specification. Development 130:3747-3755. CrossRef Medline

Park HC, Boyce J, Shin J, Appel B (2005) Oligodendrocyte specification in zebrafish requires Notch-regulated cyclin-dependent kinase inhibitor function. J Neurosci 25:6836-6844. CrossRef Medline

Parmantier E, Lynn B, Lawson D, Turmaine M, Namini SS, Chakrabarti L, McMahon AP, Jessen KR, Mirsky R (1999) Schwann cell-derived Desert hedgehog controls the development of peripheral nerve sheaths. Neuron 23:713-724. CrossRef Medline

Parrinello S, Napoli I, Ribeiro S, Digby PW, Fedorova M, Parkinson DB, Doddrell RD, Nakayama M, Adams RH, Lloyd AC (2010) EphB signaling directs peripheral nerve regeneration through Sox2-dependent Schwann cell sorting. Cell 143:145-155. CrossRef Medline

Parsons MJ, Pisharath H, Yusuff S, Moore JC, Siekmann AF, Lawson N, Leach SD (2009) Notch-responsive cells initiate the secondary transition in larval zebrafish pancreas. Mech Dev 126:898-912. CrossRef Medline

Scheer N, Groth A, Hans S, Campos-Ortega JA (2001) An instructive function for Notch in promoting gliogenesis in the zebrafish retina. Development 1099-1107.

Schroder JM, May R, Weis J (1993) Perineurial cells are the first to traverse gaps of peripheral nerves in silicone tubes. Clin Neurol Neurosurg 95 [Suppl]:S78-S83.

Sepp KJ, Schulte J, Auld VJ (2000) Developmental dynamics of peripheral glia in Drosophila melanogaster. Glia 30:122-133. CrossRef Medline

Sepp KJ, Schulte J, Auld VJ (2001) Peripheral glia direct axon guidance across the CNS/PNS transition zone. Dev Biol 238:47-63. CrossRef Medline

Shin J, Poling J, Park HC, Appel B (2007) Notch signaling regulates neural precursor allocation and binary neuronal fate decisions in zebrafish. Development 134:1911-1920. CrossRef Medline

Snyder JL, Kearns CA, Appel B (2012) Fbxw7 regulates Notch to control specification of neural precursors for oligodendrocyte fate. Neural Dev 7:15. CrossRef Medline

Takke C, Dornseifer P, Weizsäcker von E (1999) her4, a zebrafish homologue of the Drosophila neurogenic gene $\mathrm{E}(\mathrm{spl})$, is a target of $\mathrm{NOTCH}$ signalling. Development 1811-1821.

Taylor MK, Yeager K, Morrison SJ (2007) Physiological Notch signaling promotes gliogenesis in the developing peripheral and central nervous systems. Development 134:2435-2447. CrossRef Medline

Wang S, Barres BA (2000) Up a Notch: Instructing Gliogenesis. Neuron 27:197-200. CrossRef Medline

Woodhoo A, Alonso MBD, Droggiti A, Turmaine M, D’Antonio M, Parkinson DB, Wilton DK, Al-Shawi R, Simons P, Shen J, Guillemot F, Radtke F, Meijer D, Feltri ML, Wrabetz L, Mirsky R, Jessen KR (2009) Notch controls embryonic Schwann cell differentiation, postnatal myelination and adult plasticity. Nat Neurosci 12:839-847. CrossRef Medline

Yeo SY, Kim M, Kim HS, Huh TL, Chitnis AB (2007) Fluorescent protein expression driven by her4 regulatory elements reveals the spatiotemporal pattern of Notch signaling in the nervous system of zebrafish embryos. Dev Biol 301:555-567. CrossRef Medline 